\title{
Formation and development of international rock climbing among athletes with disabilities (2006-2020)
}

\author{
Lyudmila Moiseeva ${ }^{1}$, Alexander Piratinsky ${ }^{2}$ \\ ${ }^{1}$ Ural State Pedagogical University, 620017, Yekaterinburg, Russia \\ ${ }^{2}$ Ural Federal University named after the first President of Russia Boris Yeltsin, 620002, Yekaterinburg, Russia
}

\begin{abstract}
The "Classification of disability categories in rock climbing" was developed together with scientists from the University of Perugia (Italy). This classification is successfully used to date. The article defines and lists the categories of young people's disability that allow them to participate in climbing competitions. Selection and equipment of tracks for training and competitions. Providing security and insurance for different categories of disability. Medical support of sports events. Optimization of the competition program and regulations. Organization of educational and training process for different categories of young people's disability participating in rock climbing sports events.
\end{abstract}

\section{Introduction}

Rock climbing is hundreds of different techniques on terrain of different steepness, roughness, with variations in size, shape, "activity" and the relative location of hooks and supports. Climbing develops spatial orientation, flexibility, accuracy and coordination of movements, muscle groups of the upper shoulder girdle, legs, back and abdomen.

Compliance with safety requirements, proper insurance, qualified organization of the training process allow many people to enjoy climbing, ensure safety, reduce and prevent injuries. This allows to attract a wide range of students to classes, regardless of age, gender, and physical fitness degree. [1.2]

Rock climbing competitions are not an extreme activity. The experience of organizing international competitions among athletes with disabilities confirms this fact. [3]

\section{Materials and methods}

The first international competitions among athletes with disabilities were organized in cooperation with the Russian Climbing Federation and the Italian sports climbing Federation (FASI) on July 2-3, 2006 in Yekaterinburg (as part of the 2006 European championship). Athletes from Belarus, Italy, Russia and Japan took part in the competition.

The international Federation of sport climbing (IFSC) at its founding conference on January 27, 2007 in Frankfurt am Main (Germany), decided to continue working on the rock climbing development among athletes with disabilities. A special Commission was created under the leadership of IFSC Vice-President Alexander Piratinsky - IFSC Paraclimbing Commission

Piratinsky Alexander Efimovichis from the city of Yekaterinburg. Professor of the Department of physical culture of the Ural Federal University named after the first President of Russia B. N. Yeltsin. He is an honored employee of the Russian Federation Higher school, Honored coach of the RSFSR, Honorary President of the Russian Climbing Federation. The International sport climbing Federation Honorary member (IFSC Honorary Member).

He was born on September 11, 1944 in Sverdlovsk. In 1969, he graduated from the Radio Engineering Department of the Ural Polytechnic Institute. Alexander Efimovich served in the army as an officer of the country's air defense forces, a specialist of the 1 st class.

In 1963, he started mountaineering and rock climbing. Currently, associate Professor of the Department of physical education, senior coach of the national team of the Ural State Technical University-UPI, Yekaterinburg. President, head coach of the Russian Climbing Federation (RCF), Vice-President of the International Union of mountaineering associations (UIAA ICC).

1989-1992 - senior coach of the USSR and CIS national teams. 1992-1999 - first Vice-President and head coach of the RCF.

Since 1995, all-Russian competitions have been held annually in the USTU-UPI arena. In 1996, the first World Cup among all sports in the Sverdlovsk region was held here. The winners in speed climbing were USTU-UPI students Pavel Samoylin and Zosia Podgorbunskikh.

In October 1997, at The Plenary Assembly in Slovenia, Piratinsky A. E. was elected Vice-President of the climbing Council of the international mountaineering and climbing Federation. Since 1997 - Vice-President of the climbing Council of the international Union of mountaineering associations UIAA ICC. Since February 13, 1999 - President of the RCF. 
He is the head of the program "Rock climbing - 2000", in which Sverdlovsk climbers V. Pershin, E. Vinogradsky, S. Timofeev and A. Bolotov climbed mount Everest on May 18, 1998.

On June 21, 2001, Piratinsky was awarded the title "Honored employee of the Russian Federation higher school ". He was awarded the badge of honor "For services to the development of physical culture and sports".

His students won medals at international, all-Union and all-Russian competitions more than 600 times. Piratinsky trained more than 50 masters of sports, 14 masters of sports of international class, 4 honored masters of sports and 2 judges of international category.

The first IFSC Congress with the status of an independent international Federation (Matsumoto, Japan, October 2007) decided to include competitions for climbers with disabilities in the annual international calendar.

\section{Results and discussion}

A research group was created at Ural Federal University to study the possibilities of organizing and conducting competitions. [1-7]

Research problem:

1) Determination of disability categories that allow participation in rock climbing competitions. [6]

2) Selection and equipment of tracks for training and competitions. [4]

3) Providing security and insurance for different categories of disability. [3]

4) Medical support of sports events. [5]

5) Optimization of the competition program and regulations. [7]

6) Organization of the training process for different categories of participants. [1]

Together with scientists from the University of Perugia (Italy), a "Classification of disability categories in rock climbing" was developed. It is successfully used to date. Piratinsky A. E is the responsible executor of the cooperation agreement between the University of Perugia (Italy) and the Ural Federal University from 2014 to the present. The agreement includes joint scientific and pedagogical research, lectures and practical training with students, undergraduates and teachers.

The work is carried out 2 cycles a year. each cycle is at least 72 hours. Teaching is conducted in English.

At first, all climbing competitions were held in the open air on natural rocks. However, active French entrepreneurs developed, designed and manufactured special models of rocks, which were prefabricated structures made of plastic and wood. They could be installed in gyms. Rock climbing acquired an even greater number of fans. Although at first many athletes claimed that it is better to compete on natural rocks. Nowadays, all major climbing competitions are held on artificial terrain.

Second official IFSC Cup Italy, Daon - July-August 2009

Participating countries: Hungary, Italy and Russia. Disability categories: visually impaired (B1, B2 and B3) according to the international classification. Athletes with disorders of the musculoskeletal system (DMS).

Table 1. A series of international competitions was held in 2010

\begin{tabular}{|l|l|l|l|}
\hline$№$ o. & Competition location & Time frame & Participating countries \\
\hline 1 & Yekaterinburg, Russia & May 5-9 & Belarus, Italy, Russia \\
\hline 2 & Daon, Italy & July 23-25 & Spain, Italy, Russia, Japan \\
\hline 3 & Chiba, Japan & December 4-5 & Spain, Italy, Malaysia, Russia, Japan \\
\hline
\end{tabular}

Table 2. Team results for the total of 3 stages

\begin{tabular}{|c|c|c|l|c|c|c|c|}
\hline Place & Federation & $\begin{array}{c}\text { Olympic } \\
\text { code }\end{array}$ & Country & $\begin{array}{c}\text { Result stage } \\
1\end{array}$ & $\begin{array}{l}\text { Result stage } \\
2\end{array}$ & $\begin{array}{l}\text { Result stage } \\
3\end{array}$ & $\begin{array}{l}\text { Total } \\
\text { (points) }\end{array}$ \\
\hline 1 & CFR & RUS & Russia & 905 & 400 & 155 & 1460 \\
\hline 2 & JMA & JAP & Japan & & 80 & 1291 & 1371 \\
\hline 3 & FASI & ITA & Italy & 400 & 400 & 255 & 1055 \\
\hline 4 & FEDME & ESP & Spain & & 245 & 90 & 335 \\
\hline $5-6$ & BAF & BLR & Belarus & 100 & & & 100 \\
\hline $5-6$ & PMM & MAS & Malaysia & & & 100 & 100 \\
\hline
\end{tabular}

In September 2010, the IFSC Executive Committee accepted the proposal of the world championship organizers (Arco, Italy) to hold competitions for athletes with disabilities. And on February 26, 2011, the IFSC General Assembly was held in Rome. Here a wide range of issues were discussed in accordance with modern requirements for the development of sports and the possibility of including rock climbing in the program of the 2020 Olympic games.

In March 2011, the University of Perugia (Italy) hosted a scientific and practical conference "Prospects for the development of rock climbing among athletes with disabilities". Competitions for climbers with disabilities were included in the program of the 11th world championship, which was held in July 2011. 
30 men and 5 women from eleven countries participated in the championship: Belarus, China, France, Germany, Hungary, Japan, Kazakhstan, Italy, Russia, Spain, and Ukraine. The award ceremony was organized so that the winners and prize-winners were awarded by world and European Champions of different years.

The second world championship for climbers with disabilities was successfully held in Paris (sports and entertainment complex-Bercy) in September 2012.

It was attended by 46 men and 15 women from 21 countries: Argentina, Austria, Belarus, Brazil, Great Britain, China, France, Germany, Hungary, Israel, India, Indonesia, Italy, Kazakhstan, Spain, Sweden, the Netherlands, Russia, Ukraine and Venezuela. Dilyara Rakhmankulova - a member of the UrFU sports club (category B1) became the 2011 and 2012 World Champion in women's difficulty climbing.

In March 2011, the scientific conference "Prospects for the development of rock climbing among athletes with disabilities" was held at the University of Perugia (Italy). It was attended by the Vatican's sports Minister, Padre Kevin, Dr. Paola Giliotti, and Alexander Piratinsky. Pic. 6

More than 8 thousand spectators of the 2012 world climbing Championships attended the competitions of climbers with disabilities.

The IFSC Paraclimbing World Championships.

The IFSC PARACLIMBING competitions

The IFSC Paraclimbing Word Cup Event.

The IFSC Paraclimbing World Cup Series.

The IFSC Paraclimbing Continental Championships.

The IFSC Paraclimbing Continental Cup Event.

The IFSC Paraclimbing Continental Cup Series.

Others.

Table 3. International classification of disability categories for rock climbers. Visual impairment B1 Absolutely blind athletes.

\begin{tabular}{l|l}
\hline B2 & The athletes having sight up to 5\%, with the limited field of vision.
\end{tabular}

B3 $\quad$ The visually impaired athletes having sight up to $20 \%$.

Table 4. Disorders of the musculoskeletal system (DMS).

\begin{tabular}{|l|l|}
\hline AAM 0 & Fingers Amputee. \\
\hline AAM 01 & One Hand Amputee. \\
\hline AAM 02 & Two Hands Amputee. \\
\hline AAM 1 & One Arm Amputee below the elbow. \\
\hline AAM 2 & One Arm Amputee above the elbow. \\
\hline AAM 3 & Two Arms Amputee below the elbow. \\
\hline AAM 4 & Two Arms Amputee above the elbow. \\
\hline AAM 3/4 & Two Arms Amputee, one - below the elbow, other - above the elbow. \\
\hline LAM 0 & Toes Amputee. \\
\hline LAM 01 & One Foot Amputee. \\
\hline LAM 02 & Two Feet Amputee. \\
\hline LAM 1 & One Leg Amputee below the knee. \\
\hline LAM 2 & One Leg Amputee above the knee. \\
\hline LAM 3 & Two Legs Amputee below the knee. \\
\hline LAM 4 & Two Legs Amputee above the knee. \\
\hline LAM 3/4 & Two Legs Amputee, one - below the knee, other - above the knee. \\
\hline ART 1 & Arthritis PD 1. \\
\hline ART 2 & Arthritis PD 2. \\
\hline ART 3 & Arthritis PD 3. \\
\hline NRL 1 & Neurological PD 1. \\
\hline NRL 2 & Neurological PD 2. \\
\hline NRL 3 & Neurological PD 3. \\
\hline ARN 1 & Arthritis + Neurological PD. \\
\hline ARN 2 & Arthritis + Neurological PD. \\
\hline CNL 1 & Complete Neurological legs PD. \\
\hline OSD & Other subcategories of a disability. \\
\hline
\end{tabular}

\section{Conclusions}

Competitions for climbers with disabilities are of great interest to national federations, the management of national Paralympic committees and representatives of the International Paralympic Committee. Currently, scientists, doctors, coaches, competition organizers and judges are working to improve the competition rules that correspond to the specifics of adaptive rock climbing.

\section{References}


1. A.E. Piratinsky, Preparation of a rock climber (Publishing house FIS, M., 1987)

2. L.V. Moiseeva, A.E. Piratinsky, Physical Culture. Sport. Tourism. Motor recreation, 3(1), 37-40 (2018)

3. L.V. Moiseeva, A.E. Piratinsky, E.M. Deynega, E.M. Timofeeva, Russian Journal of Physical Education and Sport, 13(1), 93$101(2018)$

4. A.S. Kuznetsov, Z.M. Kuznetsova, Russian Journal of Physical Education and Sport, 14(4), 5-7 (2019). DOI: 10.14526/20704798-2019-14-4-5-7

5. A.E. Piratinsky, Methods of organizing the training process for climbing among athletes with visual disabilities (Moscow, 2011)

6. A.E. Piratinsky, International Scientific and Practical Congress: in 4 volumes (Publishing house: Russian State University of Physical Education, Sport, Youth and Tourism (SCOLIPE) (Moscow) All-Russian conference " Theory and methodology of physical culture and sport: the legacy of the founders and prospects for development». Moscow, May 27-29, 2014)

7. A.V. Lebedikhin, A.E. Piratinsky, A.P. Kolesov, Some issues of safety in rock climbing classes (Vertial. Moscow, 2009). 